Bài báo khoa học

\title{
Nghiên cứu diễn biến đáy khu vực cửa sông Hậu thuộc tỉnh Sóc Trăng
}

\author{
Trần Thị Kim ${ }^{1,2^{*}}$, Nguyễn Thị Thanh Minh ${ }^{1}$, Trà Nguyễn Quỳnh Nga $^{3,4}$, Nguyễn Thị \\ Bảy $^{3,4}$, Nguyễn Kỳ Phùng ${ }^{5}$
}

1 Trường Đại học Tài nguyên và Môi trường Tp.HCM; ttkim@hcmunre.edu.vn; nguyenthithanhminh0419@gmail.com

2 Viện Môi trường và Tài nguyên, Đại học Quốc Gia Tp.HCM; ttkim@hcmunre.edu.vn

3 Trường Đại học Bách Khoa; ntbay@hcmut.edu.vn; tnqnga@hcmut.edu.vn

4 Đại học Quốc Gia Tp.HCM; ntbay@hcmut.edu.vn; tnqnga@hcmut.edu.vn

5 Sở Khoa học và Công nghệ Tp.HCM; kyphungng@gmail.com

* Tác giả liên hệ: ttkim@hcmunre.edu.vn; Tel.: +84 902698585

Ban Biên tập nhận bài: 05/8/2020; Ngày phản biện xong: 29/8/2020; Ngày đăng bài: $25 / 9 / 2020$

Tóm tắt: Bài báo này tập trung tính toán diễn biến đáy khu vực cửa sông tỉnh Sóc Trăng dưới ảnh hưởng của thủy triều bằng phương pháp mô hình toán MIKE 21 với hai module $H D$ và $M T$ để mô phỏng chế độ dòng chảy và vận chuyển bùn cát tới diễn biến bồi xói đáy. Kết quả hiệu chỉnh, kiểm định thủy lực và vận chuyển bùn cát đạt được sự tương quan khá tốt với số liệu tại trạm Đại Ngãi và Trần Đề, đảm bảo độ tin cậy mô hình để mô phỏng hình thái đáy vào mùa lũ. Tính toán cho thấy, vào mùa lũ, dưới tác động của lưu lượng đổ về lớn nên dòng chảy sông chiếm ưu thế so với dòng chảy triều và cung cấp một lượng bùn cát lớn, do đó xu thế bồi xói phân bố rõ nét. Các khu vực xói mạnh tập trung giữa lòng sông ở đầu bờ cù lao với mức độ lớn nhất là $0,15 \mathrm{~m}$; và khu vực bồi nhiều nhất ven bờ cửa sông Định $\mathrm{An}$ với mức độ là $0,24 \mathrm{~m}$.

Từ khóa: Diễn biến đáy; Cửa sông tỉnh Sóc Trăng; Vận chuyển bùn cát; MIKE 21.

\section{Mở đầu}

Sóc Trăng là tỉnh ven biển thuộc đồng bằng sông Cửu Long (ĐBSCL), nằm ở hạ nguồn sông Hậu đổ vào biển Đông tại hai cửa Định An và Trần Đề, với chiều dài bờ biển là $72 \mathrm{~km}$ [1]. Tại đây do tác động của việc khai thác tài nguyên, khai thác rừng ngập mặn (RNM) phục vụ nuôi trồng thủy hải sản, xây dựng công trình ven biển, ... cùng với ảnh hưởng của biến đổi khí hậu mà tình hình xói lở bờ biển có những diễn biến vô cùng phức tạp [2]. Mặc dù, hệ thống đê biển và đê sông của tỉnh đã được hình thành và nâng cấp hàng chục năm qua từ Bãi Giá đến ranh giới tỉnh Sóc Trăng-Bạc Liêu, nhưng luôn bị xói lở hàng năm, đặc biệt ở những nơi không có hệ thống RNM che chắn [3-4]. Tính đến tháng 2/2020, tỉnh Sóc Trăng có 4 điểm sạt lở với tổng chiều dài là $6372 \mathrm{~m}$, trong đó sạt lở đê bao ở Đồn Biên Phòng An Thạnh 3, huyện Cù Lao Dung là 4222 m; vỡ đê biển đoạn qua xã Lai Hòa, thị trấn Vĩnh Châu là 1600 $\mathrm{m}$ [5]. Do đó, việc đánh giá biến động đáy vùng ven biển Sóc Trăng là cần thiết, cung cấp kết quả cho việc đánh giá diễn biến xói lở-bồi tụ, phục vụ cho các nghiên cứu về chỉnh trị cửa sông, công trình bảo vệ bờ hay đề xuất giải pháp giảm thiểu ảnh hưởng đến kinh tế và đời sống của người dân.

Các phương pháp thường dùng để đánh giá sự thay đổi hình thái thủy động lực ven biển dưới tác động tự nhiên và con người gồm đo đạc, khảo sát; mô hình vật lý; mô hình hoá; công 
nghệ viễn thám và GIS. Trong nghiên cứu này, mô hình MIKE 21 của viện thủy lực Đan Mạch được lựa chọn để mô phỏng và đánh giá diễn biến đáy vùng ven biển tỉnh Sóc Trăng với mục tiêu mô phỏng hình thái đáy khu vực cửa sông tỉnh Sóc Trăng dưới ảnh hưởng của triều trong mùa lũ. Các kết quả đạt được là tiền đề phục vụ cho quy hoạch chỉnh trị cửa sông ven biển.

\section{Phương pháp nghiên cứu}

\subsection{Dũ liệu tính toán}

\subsubsection{Vùng tính và lưới tính}

Để giảm thiểu sai số khi mô phỏng tính toán từ các biên mở cho khu vực nghiên cứu, theo đó, vùng tính được mở rộng bao gồm: từ vị trí trạm thủy văn Cần Thơ trên sông Hậu đến vùng ven biển tỉnh Trà Vinh và Sóc Trăng với chiều dài bờ biển là $100 \mathrm{~km}$ và khoảng cách từ bờ ra ngoài khơi là $60 \mathrm{~km}[6]$. Phạm vi không gian miền tính được thể hiện trên Hình 1 .

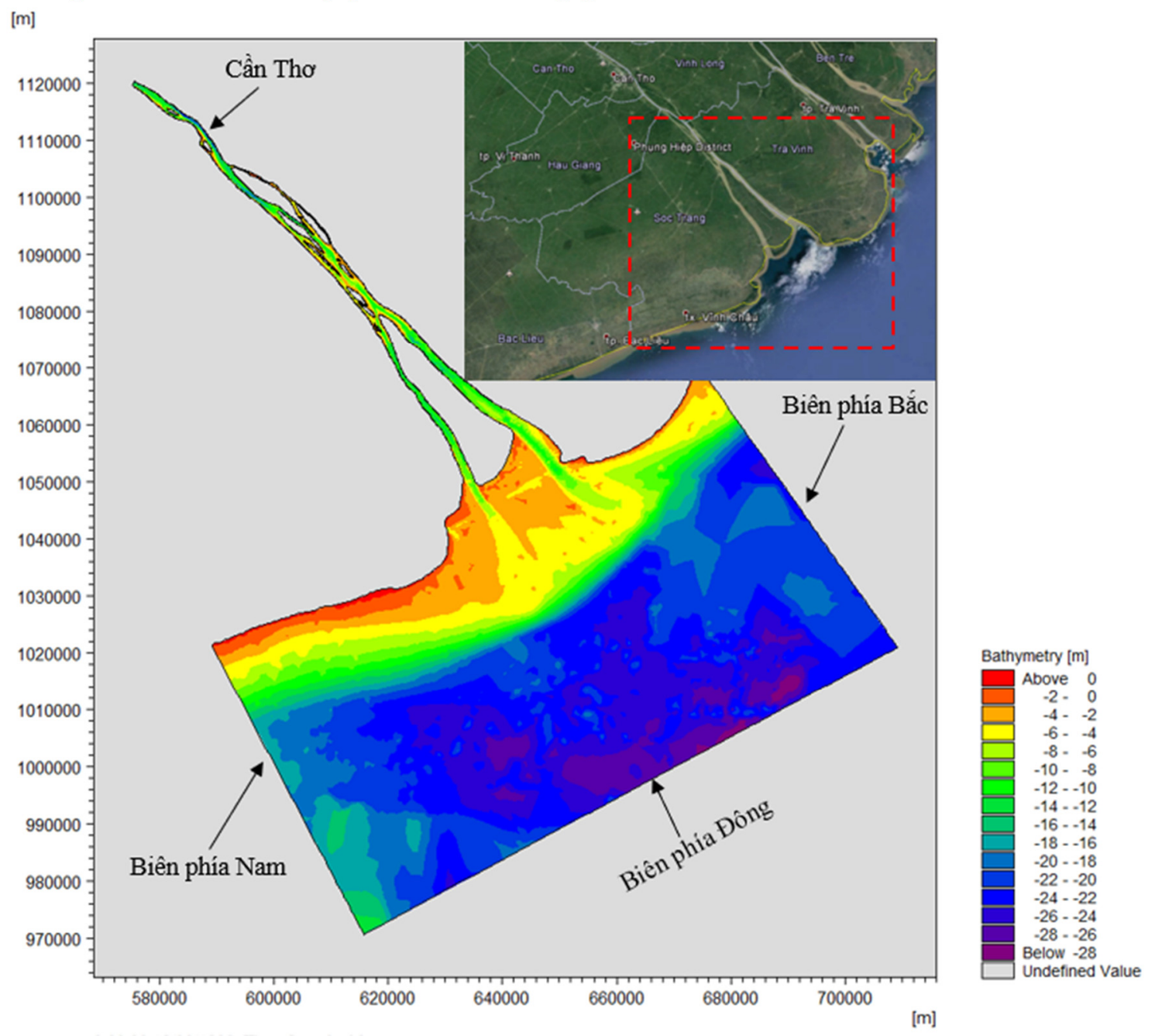

Hình 1. Giới hạn vùng tính toán.

Lưới tính được thiết lập bằng công cụ Mesh Generator trong MIKE ZERO. Để mô phỏng tương đối chính xác địa hình đáy vùng ven biển, lựa chọn lưới phi cấu trúc phù hợp với địa hình đường bờ phức tạp. Vùng tính được tạo thành từ 28926 nút và 53023 phần tử, với độ phân giải đường bờ ở vùng ngoài khơi là $400 \mathrm{~m}$, vùng chuyển tiếp là $200 \mathrm{~m}$, khu vực trong sông là $100 \mathrm{~m}$. 


\subsubsection{Dữ liệu đường bờ và địa hình đáy}

Đối với đường bờ, số liệu được thiết lập vào năm 2017 trên phần mềm Google Earth và được số hóa bằng phần mềm ArcGis.

Đối với địa hình đáy, số liệu thu thập năm 2010 và được cung cấp bởi đề tài [7], thể hiện trong Hình 1.

\subsubsection{Dữ liệu cho điều kiện biên mô hình thủy lực}

- Biên lỏng phía sông: trạm thủy văn Cần Thơ (sông Hậu) năm 2012 và 2017 được thu thập tại Đài khí tượng Thủy văn khu vực Nam bộ;

- Các biên lỏng phía biển Đông gồm: (1) biên phía Bắc (gần cửa sông Cung Hầu tỉnh Trà Vinh); (2) biên phía Nam (hết ranh giới tỉnh Sóc Trăng); (3) biên phía Đông (cách bờ biển Sóc Trăng khoảng $60 \mathrm{~km}$ ) được lấy từ phân tích điều hòa (Tide Predictions of Heights) trong MIKE 21;

- Các ranh giới còn lại của miền tính là các đường bờ khu vực cù lao, sông nhỏ và bờ biển được định dạng là các biên cứng;

- Chuỗi giá trị thực đo theo giờ năm 2012 và 2017 trạm thủy văn Đại Ngãi và Trần Đề được thu thập tại Đài khí tượng Thủy văn khu vực Nam bộ, phục vụ hiệu chỉnh và kiểm định mô hình.

\subsubsection{Dữ liệu cho điều kiện biên mô hình vận chuyển bùn cát}

SSC (nồng độ bùn cát lơ lửng): Chuỗi giá trị thực đo theo ngày năm 2012 và 2017 trạm thủy văn Cần Thơ, sử dụng làm điều kiện đầu vào mô hình vận chuyển bùn cát được thu thập tại Đài khí tượng Thủy văn khu vực Nam bộ. SSC tại Đại Ngãi và Trần Đề được trích xuất từ nghiên cứu [7].

Về cấu trúc địa chất và cấp phối hạt: đề tài tham khảo và sử dụng dữ liệu từ đề tài cấp Bộ "Nghiên cứu biến động hình thái cửa sông Cổ Chiên dưới tác động thủy động lực học" [8].

\subsection{Co sở lý thuyết Module MIKE 21 FM HD}

Module MIKE 21 FM HD mô phỏng sự biến thiên lưu lượng và mực nước dựa trên phương trình liên tục và phương trình động lượng theo hai hướng [9]:

Phương trình liên tục:

$$
\frac{\partial h}{\partial t}+\frac{\partial h \bar{u}}{\partial x}+\frac{\partial h \bar{v}}{\partial y}=h S
$$

Phương trình động lượng:

Theo phương $\mathrm{x}$ :

$$
\begin{gathered}
\frac{\partial h \bar{u}}{\partial t}+\frac{\partial h \bar{u}^{2}}{\partial x}+\frac{\partial h \overline{v u}}{\partial y}=f \bar{v} h-g h \frac{\partial \eta}{\partial x}-\frac{h}{\rho_{0}} \frac{\partial p_{a}}{\partial x}- \\
\frac{g h^{2}}{2 \rho_{0}} \frac{\partial \rho}{\partial x}+\frac{\tau_{s x}}{\rho_{0}}-\frac{\tau_{b x}}{\rho_{0}}-\frac{1}{\rho_{0}}\left(\frac{\partial s_{x x}}{\partial x}+\frac{\partial s_{x y}}{\partial y}\right)+\frac{\partial}{\partial x}\left(h T_{x x}+\frac{\partial}{\partial y}\left(h T_{x y}\right)+h u_{s} S\right.
\end{gathered}
$$

Theo phương $\mathrm{y}$ :

$$
\begin{gathered}
\frac{\partial h \bar{v}}{\partial t}+\frac{\partial h \overline{u v}}{\partial x}+\frac{\partial h \bar{v}^{2}}{\partial y}=-f \bar{u} h-g h \frac{\partial \eta}{\partial y}-\frac{h}{\rho_{0}} \frac{\partial p_{a}}{\partial y}- \\
\frac{g h^{2}}{2 \rho_{0}} \frac{\partial \rho}{\partial y}+\frac{\tau_{s y}}{\rho_{0}}-\frac{\tau_{b y}}{\rho_{0}}-\frac{1}{\rho_{0}}\left(\frac{\partial s_{y x}}{\partial x}+\frac{\partial s_{y y}}{\partial y}\right)+\frac{\partial}{\partial x}\left(h T_{x y}+\frac{\partial}{\partial y}\left(h T_{y y}\right)+h v_{s} S\right.
\end{gathered}
$$

Trong đó $\mathrm{t}$ là thời gian $(\mathrm{s}) ; \mathrm{x}, \mathrm{y}$ là tọa độ Descartes $(\mathrm{m}) ; \eta$ là dao động mực nước $(\mathrm{m}) ; \mathrm{d}$ là độ sâu của mực nước; $h$ là tổng độ sâu mực nước $(\mathrm{m}) ; \mathrm{g}$ là gia tốc trọng trường $\left(\mathrm{m} / \mathrm{s}^{2}\right) ; \mathrm{f}=$ $2 \Omega \sin \phi$ : tham số Coriolis $\left(\mathrm{s}^{-1}\right) ; \rho_{0}$ là khối lượng riêng của nước $\left(\mathrm{kg} / \mathrm{m}^{3}\right) ; p_{a}$ là áp suất khí quyển $(\mathrm{Pa} / \mathrm{m}) ; \mathrm{S}$ là lưu lượng nguồn $\left(\mathrm{m}^{3} / \mathrm{s}\right) ; u_{s}, v_{s}$ là vận tốc của nước đi vào miền tính $(\mathrm{m} / \mathrm{s})$; 
$\bar{u}, \bar{v}$ là vận tốc trung bình theo độ sâu $(\mathrm{m} / \mathrm{s})$; Tij là các thành phần nội ứng suất, được xác định theo công thức độ nhớt xoáy dựa trên vận tốc trung bình theo độ sâu; $\tau_{s x}$, $\tau_{s y}$ là ứng suất ma sát bề mặt theo phương $\mathrm{x}$ và $\mathrm{y}\left(\mathrm{N} / \mathrm{m}^{2}\right) ; \tau_{b x}, \tau_{b y}$ là ứng suất ma sát đáy theo phương $\mathrm{x}$ và $\mathrm{y}$ $\left(\mathrm{N} / \mathrm{m}^{2}\right)$; A là hệ số nhớt rối theo phương ngang $\left(\mathrm{m}^{2} / \mathrm{s}\right) ; \mathrm{S}_{\mathrm{xx}}, \mathrm{S}_{\mathrm{xy}}, \mathrm{S}_{\mathrm{yx}}, \mathrm{S}_{\mathrm{yy}}$ là các thành phần của ứng suất bức xạ sóng lên đơn vị thể tích nước theo các phương $\mathrm{x}$ và $\mathrm{y}\left(\mathrm{N} / \mathrm{m}^{2}\right)$.

\subsection{Cơ sở lý thuyết Module MIKE 21 FM MT}

Module vận chuyển bùn cát được thiết lập dựa trên phương trình chuyển tải-khuếch tán [10]:

$$
\frac{\partial \bar{c}}{\partial t}+u \frac{\partial \bar{c}}{\partial x}+v \frac{\partial \bar{c}}{\partial y}=\frac{1}{h} \frac{\partial}{\partial x}\left(h D_{x} \frac{\partial \bar{c}}{\partial x}\right)+\frac{1}{h} \frac{\partial}{\partial y}\left(h D_{y} \frac{\partial \bar{c}}{\partial y}\right)+Q_{L} C_{L} \frac{1}{h}-S
$$

Trong đó $\mathrm{t}$ là biến thời gian $(\mathrm{s}) ; \mathrm{x}, \mathrm{y}$ là tọa độ Decartes trên mặt phẳng nằm ngang $(\mathrm{m})$; $\mathrm{u}, \mathrm{v}$ là thành phần vận tốc trung bình chiều sâu theo phương $\mathrm{x}$ và $\mathrm{y}(\mathrm{m} / \mathrm{s}) ; \mathrm{h}$ là độ sâu nước $(\mathrm{m})$; $\bar{c}$ là nồng độ bùn cát lơ lửng trung bình theo độ sâu $\left(\mathrm{kg} / \mathrm{m}^{3}\right) ; D_{x}, D_{y}$ là hệ số khuếch tán theo phương $\mathrm{x}, \mathrm{y}\left(\mathrm{m}^{2} / \mathrm{s}\right) ; \mathrm{S}$ là số hạng nguồn bùn do xói hoặc bồi $\left(\mathrm{kg} / \mathrm{m}^{3} / \mathrm{s}\right) ; Q_{L}$ là lưu lượng nguồn trên một đơn vị diện tích $\left(\mathrm{m}^{3} / \mathrm{s} / \mathrm{m}^{2}\right) ; C_{L}$ là nồng độ bùn cát lơ lửng tại nguồn vào $\left(\mathrm{kg} / \mathrm{m}^{3}\right)$.

Mô phỏng hình thái đáy: Khối lượng trầm tích của cấp hạt thứ i trong lớp đáy thứ $\mathrm{j}$ của các phần tử trong lưới tính được cập nhật sau mỗi bước thời gian tính. Khối lượng lớp đáy được cập nhật tính theo phương trình sau:

$$
m_{i, j}^{\text {new }}=m_{i, j}^{\text {old }}+\left(D_{i}-E_{i}\right) \Delta t+\left(T_{i, j-1}-T_{i, j}\right)
$$

Trong đó $\mathrm{m}$ là khối lượng trầm tích $\left(\mathrm{kg} / \mathrm{m}^{2}\right) ; \mathrm{D}$ là lượng bồi $\left(\mathrm{kg} / \mathrm{m}^{2} / \mathrm{s}\right) ; \mathrm{E}$ là lượng xói $\left(\mathrm{kg} / \mathrm{m}^{2} / \mathrm{s}\right) ; \mathrm{T}$ là lượng trầm tích di chuyển của lớp đáy $\left(\mathrm{kg} / \mathrm{m}^{2} / \mathrm{s}\right) ; \Delta \mathrm{t}$ là bước thời gian tính toán.

\subsection{Thiết lập mô hình}

Quá trình tính toán thủy lực và vận chuyển bùn cát khu vực cửa sông, ven biển tỉnh Sóc Trăng bằng mô hình MIKE 21 được được trình bày cụ thể trong Hình 2.

\subsubsection{Mô hình thủy lực (MIKE 21 FM HD)}

Thời gian tính: Từ 12 giờ ngày $01 / 04 / 2012$ đến ngày 12 giờ ngày $01 / 05 / 2012$ cho quá trình trình hiệu chỉnh và 12 giờ ngày $01 / 10$ đến 0 giờ $31 / 10 / 2017$ cho quá trình kiểm định.

Điều kiện ban đầu: Mực nước tĩnh, vận tốc trên toàn miền tính $\mathrm{V}=0 \mathrm{~m} / \mathrm{s}$.

Điều kiện biên: Trong sông: chuỗi giá trị lưu lượng $(\mathrm{Q})$ thay đổi theo thời gian tại trạm thủy văn Cần Thơ; Ngoài biển: chuỗi giá trị mực nước $(Z)$ thay đổi theo thời gian và không gian, từ phân tích điều hòa.

Thông số dùng để hiệu chỉnh là hệ số Manning’s M.

\subsubsection{Mô hình bùn cát (MIKE 21 FM MT)}

Thời gian tính: Từ 12 giờ ngày $01 / 04 / 2012$ đến ngày 12 giờ ngày $01 / 05 / 2012$ cho quá trình trình hiệu chỉnh và 12 giờ ngày $01 / 10$ đến 0 giờ $31 / 10 / 2017$ cho quá trình kiểm định.

Điều kiện ban đầu: Hàm lượng bùn cát trung bình mỗi cấp phối hạt $\left(\mathrm{kg} / \mathrm{m}^{3}\right): 0,013$ (sét), 0,012 (bụi), 0,010 (cát).

Điều kiện biên: Trong sông: Hàm lượng bùn cát từng cấp phối hạt thay đổi theo thời gian tại trạm thủy văn Cần Thơ. Ngoài biển: Hàm lượng bùn cát bằng $0 \mathrm{~kg} / \mathrm{m}^{3}$.

Vận tốc lắng của các cấp hạt: $\mathrm{w}_{\mathrm{s}}=2,5 \times 10^{-5}$ (sét), $\mathrm{w}_{\mathrm{s}}=0,001$ (bụi), $\mathrm{w}_{\mathrm{s}}=0,02$ (cát).

Thành phần cấp hạt: Gồm 3 cấp phối hạt $(\mathrm{mm})$ là 0,005 (sét), 0,0275 (bụi), 0,15 (cát). 
Thông số dùng để hiệu chỉnh là: Ứng suất tới hạn bồi $\tau_{\mathrm{cd}}\left(\mathrm{N} / \mathrm{m}^{2}\right)$; Tốc độ xói $\mathrm{E}\left(\mathrm{kg} / \mathrm{m}^{2} / \mathrm{s}\right)$; Úng suất tới hạn xói $\tau_{\mathrm{ce}}\left(\mathrm{N} / \mathrm{m}^{2}\right)$; Độ nhám đáy $\mathrm{k}_{\mathrm{n}}(\mathrm{m})$.

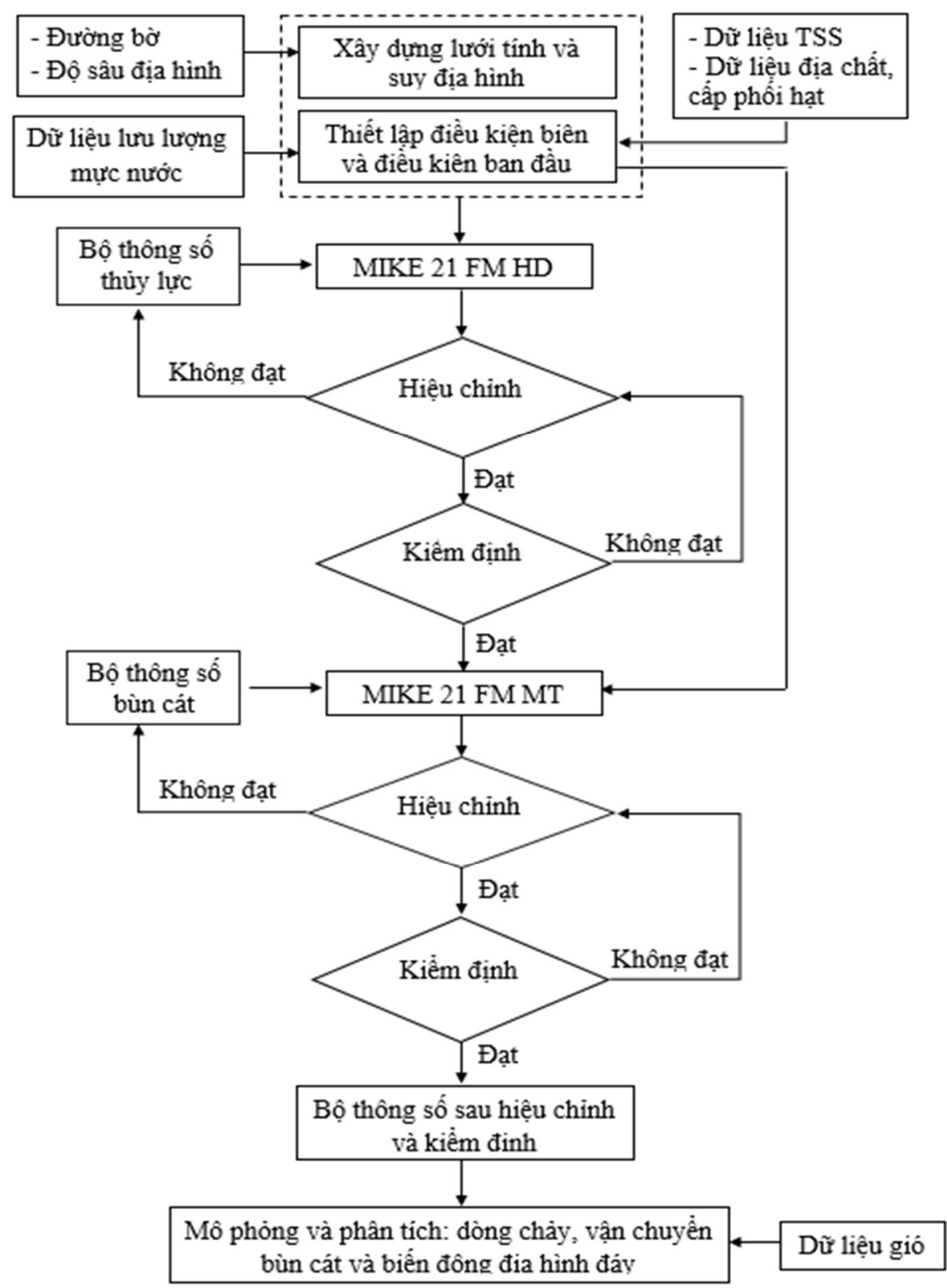

Hình 2. Trình tự thiết lập mô hình.

\section{Kết quả và thảo luận}

Module thủy động lực và vận chuyển bùn cát được sử dụng để hiệu chỉnh mực nước, vận tốc và hàm lượng phù sa (SSC) vào tháng 4 , sau đó mô hình được kiểm định vào tháng 10 . Thông số chính được dùng để hiệu chỉnh mô hình thủy lực là hệ số Manning's M. Hai trạm dùng để hiệu chỉnh là: trạm thủy văn Đại Ngãi và Trần Đề.

\subsection{Kết quả hiệu chỉnh và kiểm định mô hình thủy lục}

Kết quả so sánh giữa mực nước, vận tốc thực đo và tính toán điển hình tại trạm Đại Ngãi được trình bày trong Hình 3 . Bảng 1 tổng hợp các chỉ số đánh giá độ chính xác mô hình thủy lực. 


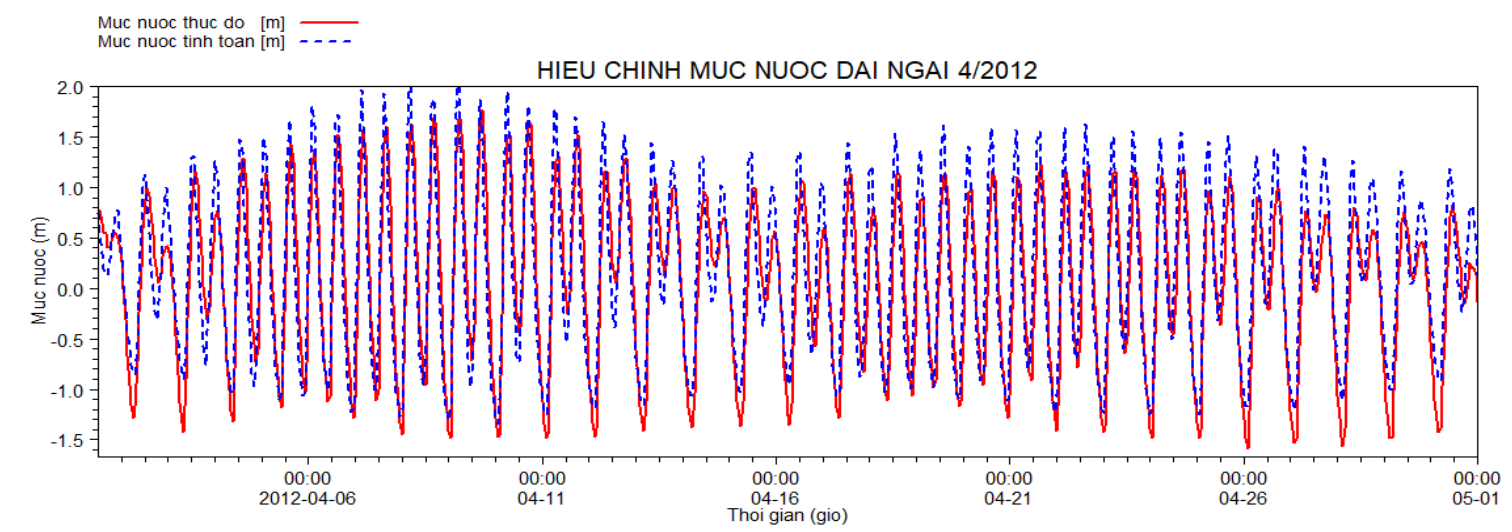

(a)

$$
\begin{aligned}
& \text { Thuc do }[\mathrm{m}] \\
& \text { Tinh toan }[\mathrm{m}] \\
& \ldots-.-
\end{aligned}
$$

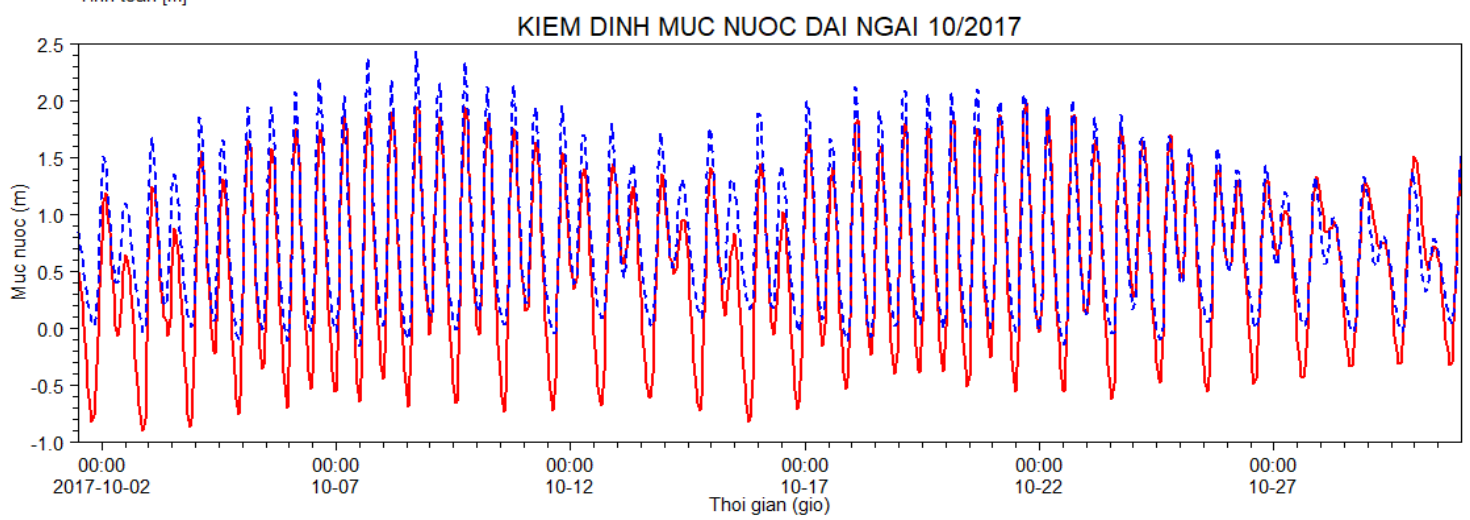

(b)

Hình 3. Kết quả hiệu chỉnh (a) và kiểm định (b) mực nước trạm Đại Ngãi.

Bảng 1. Kết quả hiệu chỉnh và kiểm định mô hình thủy lực.

\begin{tabular}{llllll}
\hline \multirow{2}{*}{ Trạm thủy văn } & \multicolumn{2}{c}{$\begin{array}{c}\text { Hiệu chỉnh } \\
\text { (2012) }\end{array}$} & \multicolumn{2}{c}{$\begin{array}{c}\text { Kiểm định } \\
(2017)\end{array}$} \\
\cline { 3 - 6 } & & NSE & $\mathrm{R}^{2}$ & $\mathrm{NSE}$ & $\mathrm{R}^{2}$ \\
\cline { 3 - 6 } Đại Ngãi & Mực & 0,78 & 0,81 & 0,78 & 0,88 \\
Trần Đề & nước & 0,93 & 0,94 & 0,87 & 0,92 \\
\hline Đại Ngãi & \multirow{2}{*}{ Vận tốc } & 0,51 & 0,85 & 0,54 & 0,92 \\
Trần Đề & & 0,81 & 0,94 & 0,85 & 0,87 \\
\hline
\end{tabular}

Kết quả phân tích tương quan giữa mực nước thực đo và tính là khá tốt, thông qua hệ số NSE và $\mathrm{R}^{2}$ đều cao hơn 0,75 . Đối với vận tốc tại Đãi Ngãi chỉ trên 0,5 , theo [11] thì chỉ nằm ở mức trung bình $(0,50<\mathrm{NSE} \leq 0,70)$. Kết quả này cho thấy bộ thông số trong mô hình thủy lực là phù hợp, đảm bảo độ tin cậy để thiết lập bộ thông số đầu vào mô hình vận chuyển bùn cát.

\subsection{Kết quả hiệu chỉnh và kiểm định mô hình bùn cát}

Kết quả hiệu chỉnh, kiểm định bùn cát được thể hiện trong Hình 4 . Đối với mô hình phù sa, nghiên cứu này chỉ sử dụng chỉ số PBIAS (phần trăm sai số) đối với mô phỏng bùn cát vì mô phỏng phù sa khá biến động, ngoài ra PBIAS còn có khả năng chỉ ra hiệu quả mô phỏng [12-14]. Kết quả cho thấy: Sai số của nồng độ bùn cát lơ lửng tại trạm Đại Ngãi và Trần Đề khá nhỏ $(<10 \%)$, đạt mức tốt. Kết quả hiệu chỉnh và kiểm định mô hình bùn cát được trình bày trong Bảng 2 . 


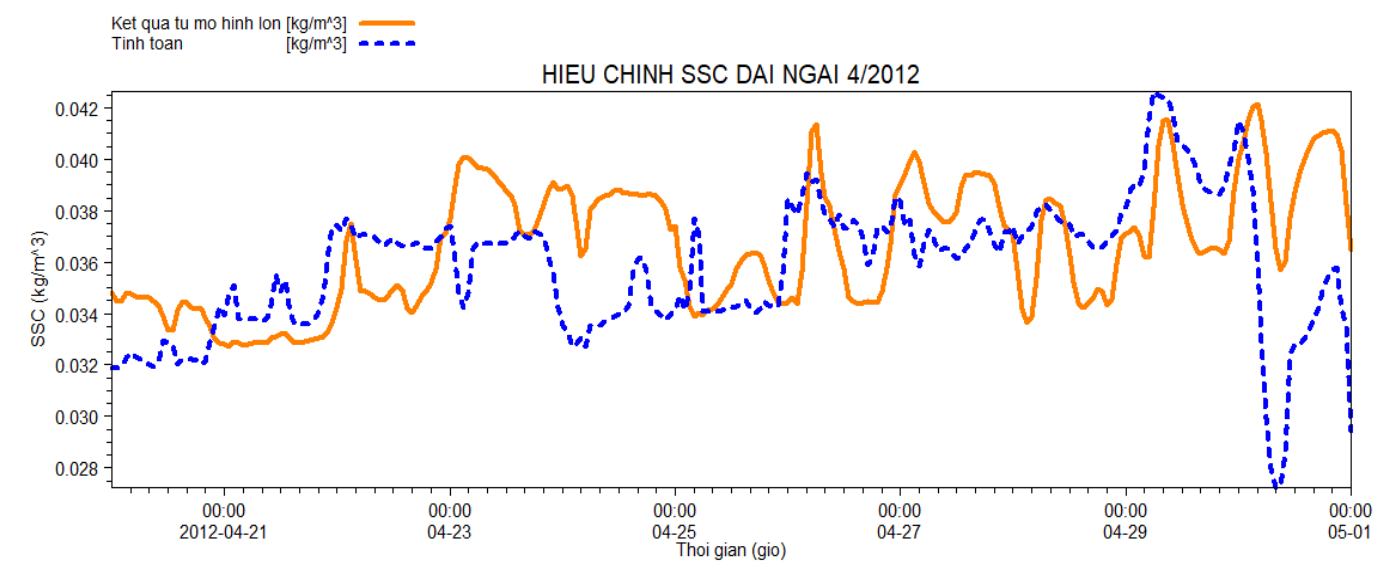

Hình 4. Kết quả hiệu chỉnh phù sa trạm Đại Ngãi.

Bảng 2. Kết quả hiệu chỉnh và kiểm định mô hình bùn cát.

\begin{tabular}{crc}
\hline \multirow{2}{*}{ Trạm thủy văn } & $\begin{array}{c}\text { Hiệu chỉnh } \\
(2012)\end{array}$ & $\begin{array}{c}\text { Kiểm định } \\
(2017)\end{array}$ \\
\cline { 2 - 3 } & \multicolumn{2}{c}{ PBias (\%) } \\
\hline Đại Ngãi & 2,15 & 0,23 \\
Trần Đề & 0,15 & 0,14 \\
\hline
\end{tabular}

Thông số đầu vào mô hình thủy lực và bùn cát sau quá trình hiệu chỉnh và kiểm định được là: Bước thời gian tính toán là 120 giây; Đối với module thủy lực (HD): Hệ số Manning's M: Giá trị thay đổi theo độ sâu địa hình từ 20-45 $\left(\mathrm{m}^{1 / 3} / \mathrm{s}\right)$; Đối với module bùn cát (MT): Thành phần cấp hạt: Gồm 3 cấp phối hạt $(\mathrm{mm}): 0,005$ (sét), 0,0275 (bụi), 0,15 (cát); Tính chất bùn cát lơ lửng: Ứng suất tới hạn bồi: $\tau_{\mathrm{cd}}=0,1 \mathrm{~N} / \mathrm{m}^{2}$; Tham số bề dày lớp đáy:

- Tốc độ xói: $\mathrm{E}=2 \times 10^{-6}\left(\mathrm{~kg} / \mathrm{m}^{2} / \mathrm{s}\right)$;

- Úng suất tới hạn xói: $\tau_{\mathrm{ce}}=0,25 \mathrm{~N} / \mathrm{m}^{2}$;

- Độ nhám đáy $(\mathrm{m}): \mathrm{k}_{\mathrm{n}}=0,0001$.

\subsection{Kết quả mô phỏng trương vận tốc lúc triều lên và triều xuống và diễn biến đáy mùa lũ} năm 2017

Do quá trình vận chuyển bùn cát bị chi phối mạnh bởi lưu lượng sông từ thượng nguồn đổ về vào mùa lũ. Trong mùa lũ, vận tốc dòng chảy lớn hơn so với mùa kiệt nên quá trình bồi xói sẽ thể hiện rõ hơn. Theo đó, thời gian mô phỏng trong nghiên cứu này là 4 tháng mùa lũ từ 12 giờ $1 / 7 / 2017$ đến 0 giờ $31 / 10 / 2017$.

Vùng tính được chia thành hai đoạn để phân tích gồm: đoạn 1 là từ khu vực cù lao ra đến cửa sông, đoạn 2 từ cửa sông ra đến ngoài biển ở độ sâu $6 \mathrm{~m}$ và khu vực tính không xét đến vị trí dọc bờ biển. Khu vực phân tích được thể hiện trong Hình 5 .

Kết quả mô phỏng hướng dòng chảy và trường vận tốc được biểu diễn tại thời điểm thời điểm dòng chảy xuống mạnh nhất và dòng triều lên mạnh nhất trong mùa lũ. Vận tốc được thể hiện cùng một thang màu đỏ từ đậm tới nhạt tương ứng với giá trị vận tốc từ lớn đến nhỏ. Kết quả mô phỏng diễn biến bồi, xói theo kịch bản sau 4 tháng mùa lũ, được trình bày bằng thang màu xanh từ nhạt đến đậm thể hiện mức độ bồi từ ít đến nhiều, thang màu đỏ từ đậm đến nhạt thể hiện mức độ xói từ nhiều đến ít. 


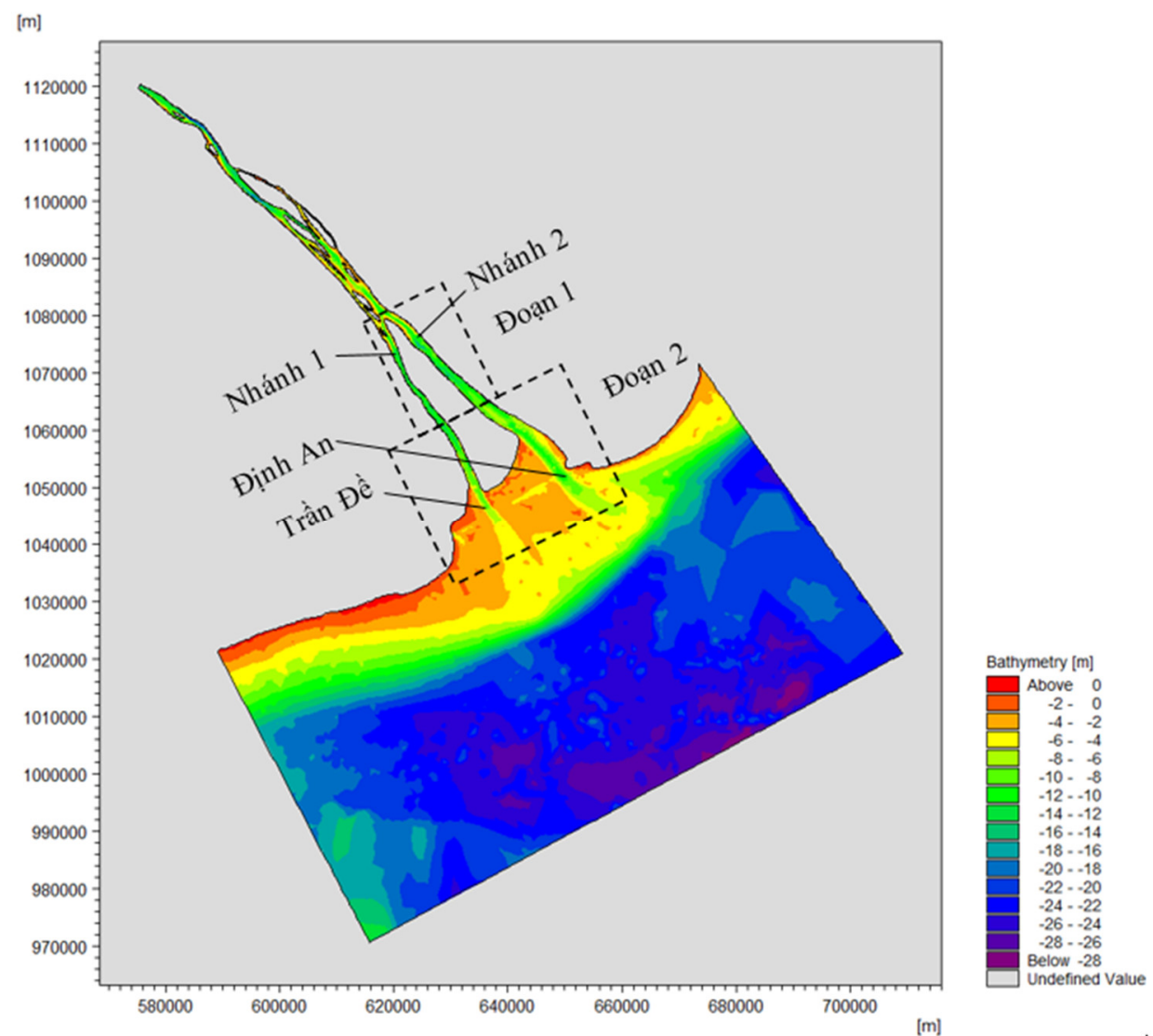

Hình 5. Khu vực dùng để phân tích kết quả tính toán.

\subsection{Kết quả mô phỏng truờng vận tốc lúc triều lên và triều xuống trong mùa lũ}

\subsection{1 Đối với pha triều lên}

Kết quả mô phỏng vận tốc lúc triều lên vào mùa lũ cho thấy:

Tại đoạn 1 (Hình $6 a$ ), vận tốc dòng triều ở cửa sông truyền vào khá nhỏ từ $0,2-0,3 \mathrm{~m} / \mathrm{s}$. Trong khi đó, tại đầu bờ cù lao, tốc độ dòng chảy từ trên thượng nguồn truyền xuống khá lớn nên tác động vào đầu bờ với vận tốc từ $0,5-0,7 \mathrm{~m} / \mathrm{s}$. Ra đến giữa cù lao, dòng triều và dòng chảy sông tương tác với nhau nên vận tốc có xu hướng bị triệt tiêu, dao động trong khoảng $0,01-0,05 \mathrm{~m} / \mathrm{s}$.

Tại đoạn 2 (Hình $6 \mathrm{~b}$ ), phân bố vận tốc toàn vùng phổ biến trong khoảng $0,1-0,35 \mathrm{~m} / \mathrm{s}$. Ở khu vực gần bờ, vận tốc dao động dưới $0,1 \mathrm{~m} / \mathrm{s}$. Trong khi đó, ở khu vực giữa hai luồng cửa sông, vận tốc phân bố lớn hơn từ $0,3-0,5 \mathrm{~m} / \mathrm{s}$.

\subsection{2 Đối với pha triều xuống}

Kết quả phân bố vận tốc dòng chảy ở đoạn 1 (Hình 7a) trong pha triều xuống vào mùa lũ cho thấy giá trị phân bố toàn vùng trong khoảng $0,5-0,8 \mathrm{~m} / \mathrm{s}$, trong đó vận tốc lớn nhất đạt $1,0-1,4 \mathrm{~m} / \mathrm{s}$ phân bố giữa lòng sông ở đầu bờ cù lao nhánh 2 , vì đầu bờ nhánh 1 xuất hiện nhiều cù lao nhỏ cản trở, làm trục dòng chảy có xu hướng di chuyển về nhánh 2 nhiều hơn. Ngoài ra, ở nhánh 1 vận tốc đạt giá trị lớn nhất tại bờ cù lao nhỏ là $1,03 \mathrm{~m} / \mathrm{s}$ (vị trí khoanh tròn) và tại đoạn co hẹp là $1,02 \mathrm{~m} / \mathrm{s}$. Dòng chảy đoạn 2 (Hình $7 \mathrm{~b}$ ) có vận tốc phân bố toàn vùng khoảng $0,1-0,3 \mathrm{~m} / \mathrm{s}$. Khu vực sát bờ có vận tốc dưới $0,1 \mathrm{~m} / \mathrm{s}$. Khu vực giữa hai luồng cửa sông có giá trị phân bố vận tốc giống nhau, phổ biến từ $0,7-0,8 \mathrm{~m} / \mathrm{s}$, trong đó tại cửa Trần Đề đạt vận tốc cực đại là $0,82 \mathrm{~m} / \mathrm{s}$, tại cửa Định An là $0,86 \mathrm{~m} / \mathrm{s}$. 


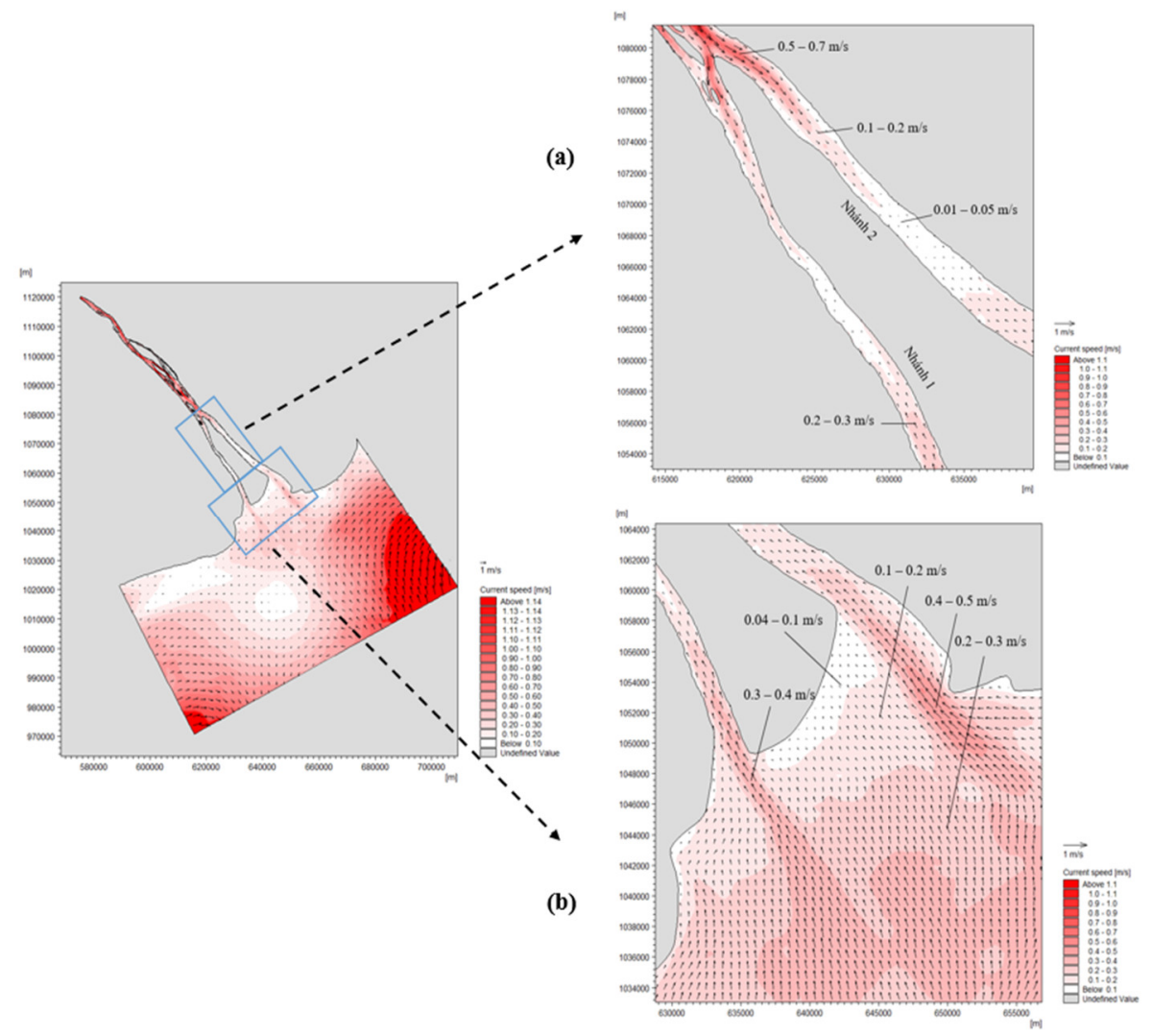

Hình 6. Kết quả mô phỏng vận tốc lúc triều lên vào mùa lũ từ 12 giờ 1/7/2017 đến 0 giờ 31/10/2017.

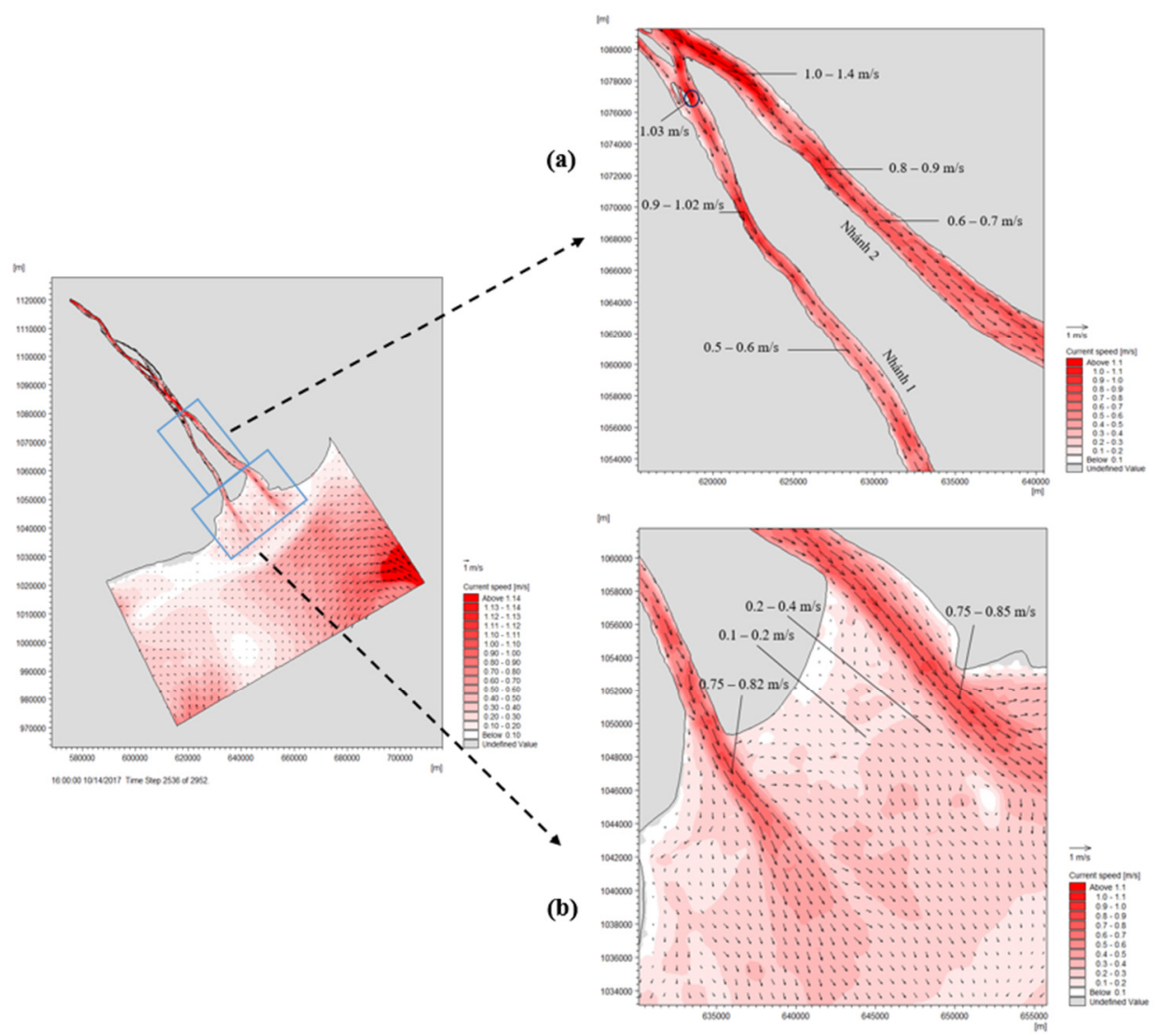

Hình 7. Kết quả mô phỏng vận tốc lúc triều xuống vào mùa lũ từ 12 giờ $1 / 7 / 2017$ đến 0 giờ 31/10/2017. 
Nhìn chung từ kết quả tính toán, có thể thấy phân bố vận tốc dòng chảy thể hiện rõ sự chiếm ưu thế của dòng chảy sông. Trong mùa lũ với lưu lượng đổ về lớn nên vận tốc trong sông dao động khá lớn và chiếm ưu thế hơn dòng chảy triều khi vào đến trong sông. Ngoài ra, luồng dòng chảy có xu hướng phân bố và đạt giá trị lớn nhất giữa lòng sông và giữa hai luồng cửa sông. Độ sâu địa hình cũng ảnh hưởng tới tốc độ dòng chảy.

\subsection{Kết quả mô phỏng diễn biến đáy}

Kết quả thể hiện bồi xói vào cuối mùa lũ cho thấy xu thế bồi xảy ra chủ yếu ở khu vực dọc đường bờ trên đoạn 1 , với mức độ bồi trong khoảng 0,05 đến $0,1 \mathrm{~m}$. Do lưu lượng từ thượng nguồn đổ xuống lớn nên vận tốc dòng chảy trong sông lớn, trục dòng chảy có xu hướng di chuyển về nhánh 2 , do đó với vận tốc phân bố nhiều hơn làm cho khu vực đầu bờ cù lao xuất hiện xói nhiều hơn ở giữa lòng sông, với mức độ từ $0,04-0,3 \mathrm{~m}$ (Hình 8b).

Kết quả thể hiện bồi xói vào mùa lũ trên đoạn 2 trong Hình $8 \mathrm{c}$ cho thấy khu vực cửa sông xảy ra xu thế bồi chủ yếu ở vị trí giữa bờ cù lao và dọc hai bên cửa sông, với mức độ từ $0,03-$ $0,13 \mathrm{~m}$, trong đó mức độ bồi lớn nhất tại dọc bờ cửa sông Trần Đề là $0,14 \mathrm{~m}$ và dọc bờ cửa Định An là $0,24 \mathrm{~m}$. Ở giữa luồng cửa Định An xuất hiện xói với mức độ khá nhỏ $0,02-0,03 \mathrm{~m}$ (Hình 8c).

(a)

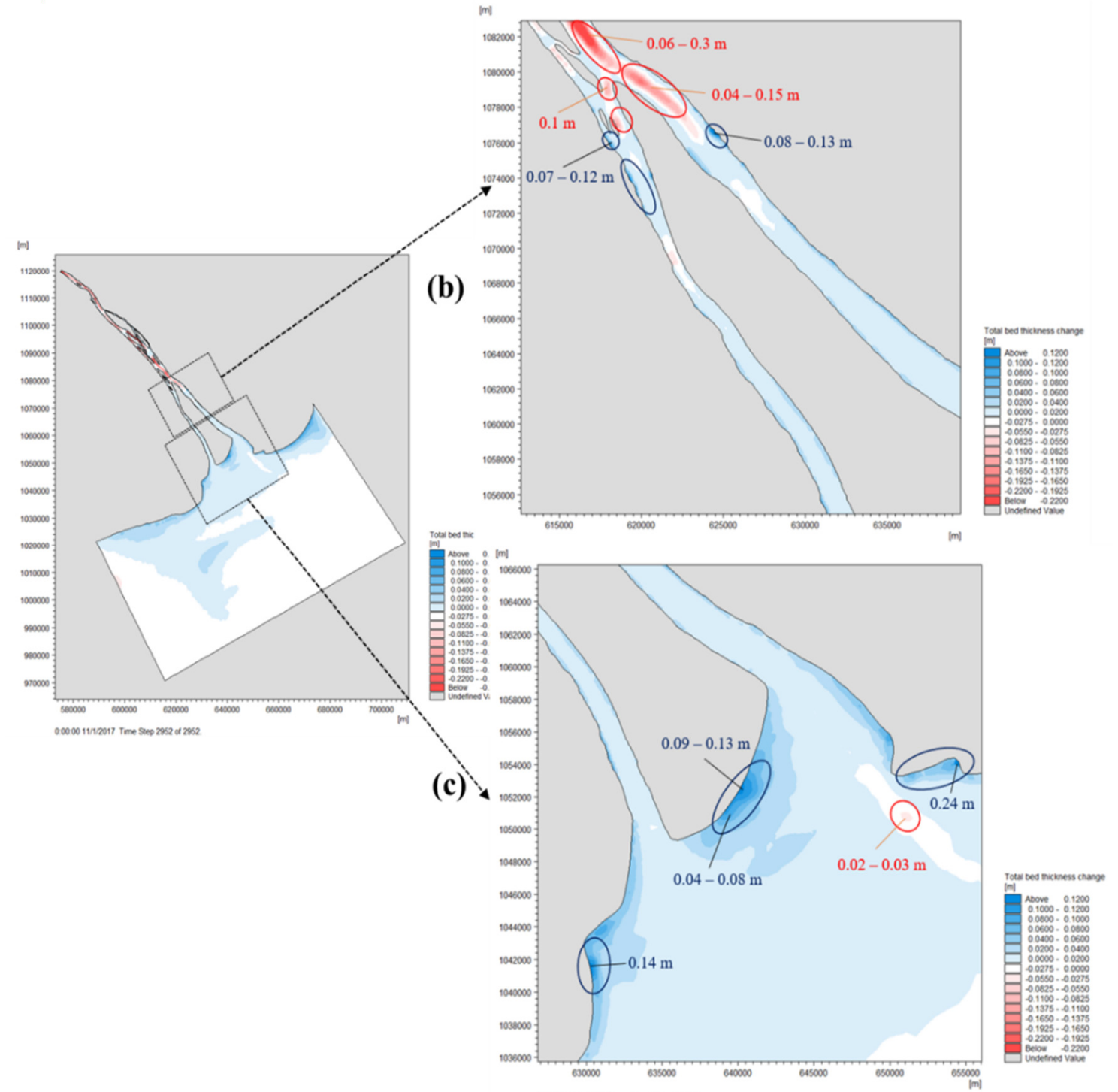

Hình 8. Kết quả mô phỏng bồi xói sau 4 tháng tính toán mùa lũ 12 giờ $1 / 7 / 2017$ đến 0 giờ 31/10/2017. 


\section{Kết luận}

Bằng việc sử dụng phương pháp mô hình toán, cụ thể là mô hình MIKE 21 với module $\mathrm{HD}$ và $\mathrm{MT}$, đề tài đã tính toán được chế độ thủy động lực và chuyển tải phù sa tại khu vực cửa sông Hậu, từ đó phân tích được xu thế bồi, xói đáy trong mùa lũ. Các kết quả tính toán bồi xói khá phù hợp với kết quả dòng chảy và quá trình vận chuyển bùn cát bị chi phối mạnh bởi lưu lượng sông từ thượng nguồn. Cụ thể, vận tốc dòng chảy phân bố lớn nhất ở các đầu bờ cù lao và gây ra hiện tượng xói theo trục dòng chảy ở giữa lòng sông; ở khu vực ven biển thì mức độ bồi thể hiện nhiều hơn ở dọc hai bờ cửa sông và giữa bờ biển cù lao và có hiện tượng xói ở giữa luồng cửa sông Định An. Các khu vực xói mạnh tập trung giữa lòng sông ở đầu bờ cù lao với mức độ lớn nhất là $0,15 \mathrm{~m}$; và mức độ bồi nhiều nhiều nhất ven bờ cửa sông Định $\mathrm{An}$ với bề dày là $0,24 \mathrm{~m}$.

Có thể nhận thấy rằng ở khu vực cửa sông Hậu có xu thế bồi chiếm ưu thế so với xói, điều này khá phù hợp với nghiên cứu [2,5]. Tuy nhiên, hạn chế của nghiên cứu là chưa có dữ liệu mặt cắt địa hình để so sánh sau khi mô phỏng và nghiên cứu chưa tính toán đến ảnh hưởng của sóng tác động vào bờ biển.

Đóng góp của tác giả: Xây dựng ý tưởng nghiên cứu: Kim T.T; Phùng N.K; Bảy N.T; Lựa chọn phương pháp nghiên cứu: Kim T.T; Phùng N.K; Xử lý số liệu: Minh N.T.T.; Nga T.N. Q.; Mô hình hóa: Kim T.T.; Minh N.T.T.; Nga T.N.Q.; Phân tích kết quả: Kim T.T.; Bảy N. T.; Nga T.N.Q.; Chỉnh sửa bài báo: Kim T.T.; Phùng N.K.

Lời cảm ơn: Nghiên cứu sinh được hỗ trợ bởi chương trình học bổng đào tạo thạc sĩ, tiến sĩ trong nước của Quỹ Đổi mới sáng tạo Vingroup.

Lời cam đoan: Tập thể tác giả cam đoan bài báo này là công trình nghiên cứu của tập thể tác giả, chưa được công bố ở đâu, không được sao chép từ những nghiên cứu trước đây; không có sự tranh chấp lợi ích trong nhóm tác giả.

\section{Tài liệu tham khảo}

1. Sở TN\&MT Sóc Trăng. Dự án Báo cáo tổng hợp quy hoạch sử dụng đất bãi bồi ven biển tỉnh Sóc Trăng giai đoạn 2010-2020, định hướng đến năm 2030, 2011.

2. Trung, L.T.; Phái, V.V.; Anh, V.T. Đặc điểm địa mạo dải ven biển Sóc Trăng-Cà Mau (từ cửa Định An đến cửa Tiểu Dừa). Tạp chi Khoa hoc ĐHQGHN: Các Khoa học Trái đất và Môi truò̀ng 2014, 30, 55-72.

3. Trung, L.T.; Anh, V.T.; Phái, V.V.; Lân, V.Q.; Nguyên, P.H. Nghiên cứu tính toán vận chuyển trầm tích và biến đổi địa hình đáy biển ven bờ Sóc Trăng-Cà Mau sử dụng mô hình Mike21 bằng phương pháp phần tử hữu hạn. Tạp chí Địa chất 2014, 346-348, 191-200.

4. Albers, T.; Von Lieberma, N. Dự án Quản lý Nguồn Tài nguyên Thiên nhiên Vùng Ven biển tỉnh Sóc Trăng: Nghiên cứu về Dòng chảy và Mô hình Xói lở, Deutsche Gesellschaft für Internationale Zusammenarbeit (GiZ) GmbH, Sóc Trăng, 2011, 72.

5. Bộ Nông nghiệp và Phát triển Nông thôn. Bản đồ trực tuyến quản lý sạt lở. Trang online: http://satlo.vndss.com/13/9.5556/106.2491/c2. (Truy cập ngày 05/03/2020).

6. Bảy, N.T. Báo cáo tổng kết đề tài: Nghiên cứu xác định nguyên nhân, cơ chế và đề xuất giải pháp khả thi về kỹ thuật, hiệu quả về kinh tế nhằm hạn chế xói lở, bồi lắng cho hệ thống sông đồng bằng sông Cửu Long, mã số: KHCN-TNB.ĐT/14-19/C10, 2017-2020.

7. Kim, T.T.; Nga, N.T.Q.; Bay, N.T. The effect of reducing sediment load on alluvial erosion process of the upstream Mekong Delta in Vietnam. The $11^{\text {th }}$ Regional Conference on Environmental Engineering 2018 (RCEnvE-2018), Cambodia, 2018.

8. Hồng, N.V. Nghiên cứu biến động hình thái cửa sông Cổ Chiên dưới tác động thủy động lực học, Phân viện Khoa học Khí tượng Thủy văn và Biến đổi khí hậu, 2016. 
9. DHI. MIKE 21 \& MIKE 3 Flow Model FM. Hydrodynamic Module. Scientific documentation, 2012.

10. DHI, MIKE 21 \& MIKE 3 Flow Model FM. Hydrodynamic and Transport Module. Scientific documentation, 2012.

11. Moriasi, D.N.; Gitau, M.W.; Pai, N.; Daggupati, P. Hydrologic and water quality models: Performance measures and evaluation criteria. Trans. ASABE 2015, 58, 1763-1785. https://doi.org/10.13031/trans.58.10715.

12. Hùng, L.M.; Hoằng, T.B.; Khang, N.D.; Anh, T.T. Kết quả ứng dụng mô hình SWAT trong tính toán xói bề mặt lưu vực hạ lưu sông Mekong. Tạp chí Khoa hoc và Công nghẹ Thủy lợi 2012, 25-32.

13. Nga, T.N.Q.; Khoi, D.N.; Thuy, N.T.D.; Nhan, D.T.; Kim, T.T.; Bay, N.T. Understanding the Flow and Sediment Dynamics in the Mekong River - A Case Study in the Vinh Long Province. $A P A C$ 2019. Springer, Singapore. https://doi.org/10.1007/978-981-15-0291-0_196.

14. Gupta, H.V.; Sorooshian, S.; Yapo, P.O. Status of automatic calibration for hydrologic models: Comparision with multilevel expert calibration. J. Hydrologic Eng. 1999, 4, 135-143.

\section{Research on bottom morphology in Soc Trang estuary under the influence of the tide}

Tran Thi Kim ${ }^{1,2^{*}}$, Nguyen Thi Thanh Minh${ }^{1}$, Tra Nguyen Quynh Nga ${ }^{3,4}$, Nguyen Thi Bay $^{3,4}$, Nguyen Ky Phung ${ }^{5}$

${ }^{1}$ Ho Chi Minh City University of Natural Resources and Environment; ttkim@hcmunre.edu.vn; nguyenthithanhminh0419@gmail.com

${ }^{2}$ Institute for Environment and Resources, Vietnam National University Ho Chi Minh City; ttkim@hcmunre.edu.vn

${ }^{3}$ University of Technology; ntbay@hcmut.edu.vn; tnqnga@hcmut.edu.vn

${ }^{4}$ Vietnam National University Ho Chi Minh City; ntbay@hcmut.edu.vn; tnqnga@hcmut.edu.vn

${ }^{5}$ Ho Chi Minh City Department of Science and Technology; kyphungng@gmail.com

Abstract: This paper focuses on the development of the bed change in Soc Trang Estuary under the influence of tide by mathematical method - MIKE 21 (Hydrodynamic and mud transport modules) to simulate the flow regime and sediment transport. The results of hydraulic and sediment transport verification show good correlation at Dai Ngai and Tran De stations, ensuring the reliability to simulate the bottom morphology in flood season. The results shows that under the impact of upstream, the river flow prevails over the tidal flow and provided a large amount of sediment, so the erosion is more pronounced. The strong erosion areas is concentrated in the river bed at the banks of the islet with the largest level being $0.15 \mathrm{~m}$; and the most accreting area along the Dinh An estuary with a level of $0.24 \mathrm{~m}$.

Keywords: Bottom morphology; Soc Trang estuary; Sediment transport; MIKE 21. 